\title{
Simulation in Neurocritical Care: Past, Present, and Future
}

\author{
Nicholas A. Morris ${ }^{1,4^{*}}$, Barry M. Czeisler ${ }^{2}$ and Aarti Sarwal ${ }^{3}$ \\ (C) 2018 Springer Science+Business Media, LLC, part of Springer Nature and Neurocritical Care Society
}

\begin{abstract}
Simulation-based medical education is a technique that leverages adult learning theory to train healthcare professionals by recreating real-world scenarios in an interactive way. It allows learners to emotionally engage in the assessment and management of critically ill patients without putting patients at risk. Learners are encouraged to work at the edge of their expertise to promote growth and are provided with feedback to nurture development. Thus, the training is targeted to the learner, not the patient. Despite its origins as a teaching tool for neurological diseases, simulation-based medical education has been historically abandoned by neurocritical care educators. In contrast, other critical care educators have embraced the technique and built an impressive foundation of literature supporting its use. Slowly, neurocritical care educators have started experimenting with simulation-based medical education and sharing their results. In this review, we will investigate the historical origins of simulation in the neurosciences, the conceptual framework supporting the technique, current applications, and future directions.
\end{abstract}

Keywords: Simulation, Education, Critical care, Neurocritical care

\section{Introduction}

In 1999, The Institute of Medicine's To Err is Human exposed the astonishing volume and consequences of medical errors in the USA, spurring a revolution in patient safety investigation and innovation. Taking a cue from other industries with high-profile safety concerns, including aviation and nuclear energy, medical educators and safety officers alike recognized the potential for simulation to augment traditional medical curricula.

Simulation is defined "as a technique-not a technology - to replace or amplify real experiences with guided experiences that evoke or replicate substantial aspects of the real world in a fully interactive manner [1]." While simulation modalities were first described in medicine over 60 years ago, only recently has simulation been adopted as a critical component of healthcare education.

\footnotetext{
*Correspondence: Nicholas.Morris@umm.edu

${ }^{4}$ Division of Neurocritical Care and Emergency Neurology, University of Maryland Medical Center, 22 S. Greene St, G7K18, Baltimore, MD 21201, USA

Full list of author information is available at the end of the article
}

Over the last two decades, simulation-based medical education has established itself as an important tool for knowledge and skill acquisition and maintenance [2]. However, neurologists and neurocritical care educators have been slow to adopt, and have even actively rejected simulation [3]. Nonetheless, recent interest has surged due to emerging therapeutic paradigms in neurosciences necessitating modalities like simulation to teach highstakes clinical decision making [4].

Neurological complaints account for a considerable proportion of all emergency room visits and comprise a disproportionately high number of intensive care unit admissions [5, 6]. Given the time-sensitivity of neurological diseases such as acute stroke and status epilepticus, the first hours of care are crucial in determining outcome. The goals of simulation-based medical education in emergency neurology are to reduce misdiagnosis, optimize resource allocation, hasten decisive interventions, and foster multidisciplinary collaboration [7].

In this review, we will explore the historical origins of simulation-based medical education, its conceptual 
framework, current applications, and future directions especially as pertinent to neurosciences.

\section{Historical Origins of Simulation-Based Medical Education in Neurology/Neurocritical Care}

Neurology continues to be considered one of the most difficult specialties and the one which provokes the most discomfort in trainees and practitioners [8]. Half a century ago, Howard S. Barrows-a neurologist and luminary in medical education-denounced clinical neurology teaching methods for their "seed catalog approach" divorced from complex patient care [9]. He argued that only the actual experience and pressures of practice seemed capable of forcing students to become practical, accurate and efficient. Failure to integrate basic science with pragmatic bedside clinical neurology hampered performance and led to a syndrome among students that Ralph Jozefowicz would later call "neurophobia" [10].

Barrows proposed a two-fold solution. First, he suggested a student centered pedagogy called "ProblemBased Learning." This featured graded problems in neurological dysfunction, working back from the problem to a knowledge and understanding of the underlying anatomical, physiological, and pathophysiological aspects of the case. The problems become increasingly complex and obtuse, and competence and overall knowledge built as a result [11]. Secondly, he pioneered the use of simulated patients, which he later called standardized patients. Barrows' standardized patients simulated important physical findings in neurocritical care such as asterixis, Cheyne-Stokes and Kussmaul respirations, coma, decerebrate posturing, dilated pupils, dysarthria, facial paralysis, lid lag, ptosis, hemiparesis, seizures, and vomiting [12]. Barrows' work, embraced by medical educators nationwide and crystallized in the USMLE Step 2 Clinical Skills Examination, was largely eschewed by neurologists who questioned the verisimilitude of simulated neurological findings [3].

Barrows' critiques of clinical neurology training ring true today and may be amplified by the exponential increase in scientific knowledge, decreased learning opportunities due to duty hour restrictions, and expansion of rote clerical duties due to high patient turnover [13]. Medical students and neurology residents alike are expected to learn the general principles for recognizing, evaluating, and managing neurological emergencies such as acute stroke, subarachnoid hemorrhage, status epilepticus, and brain trauma $[14,15]$. The identification and management of neurological emergencies are built into the Accreditation Council for Graduate Medical Education (ACGME) neurology milestones and important components of clinical encounters necessitated by the
Liaison Committee of Medical Education [16]. Despite that, many medical students graduate without competence or confidence in basic neurological or critical care skills $[17,18]$.

One notable factor in medical education is the lack of clinical exposure to neurology and especially neurological emergencies. In the USA, clinical neurology training is not required in medical school nor in specialty residency training such as emergency medicine and internal medicine that often serve as the frontline for critically ill neurology patients. In Canada, even in internal medicine residency programs that incorporate clinical neurology training, graduating residents do not rate themselves as competent in neurology [19]. A survey administered through the American Academy of Neurology Graduate Education Subcommittee reported only $56 \%$ of neurology residency programs rotate through a dedicated neurointensive care unit and that many patients with foundational diagnoses, such as subarachnoid hemorrhage, are cared for primarily by other services [20]. As such, neurology resident education in critical care neurology is mostly accomplished through didactic lecture sessions [20]. Among trainees that spend time in a dedicated neurointensive care unit, education ranks as their number one concern about the rotation, regardless of their exposure time or senior clinical staff interaction [21]. It seems that exposure alone is not enough to ameliorate educational deficiencies. This highlights the need for exploring modalities like simulation-based medical education to help address the deficiencies.

\section{Conceptual Framework}

Barrows' critiques can be explained by education theory. Based on work from Kurt Lewin, John Dewey, and Jean Piaget, David Kolb developed the experiential learning theory [22]. Per Kolb, learning is a continuous process grounded in experience. Effective learning requires a four-stage cycle (Fig. 1). In the first stage, the learner actively experiences an activity such as managing a patient in status epilepticus. The second stage is a space for the learner to reflect back on that experience and question what worked and what failed. For instance, were there delays in halting the seizure? Were the antiepileptic drugs appropriately dosed? Busy clinical rotations rob the learner of time for this critical stage. In the third stage, the learner uses resources to understand what they could have done differently. In this example, published guidelines could suggest appropriate doses and ameliorate concerns related to higher doses of antiepileptic drugs with regards to respiratory compromise. Finally, in the active experimentation stage the learner takes the reflections and thoughts to their next case. Simulation offers the opportunity to prescribe experiential learning in a 


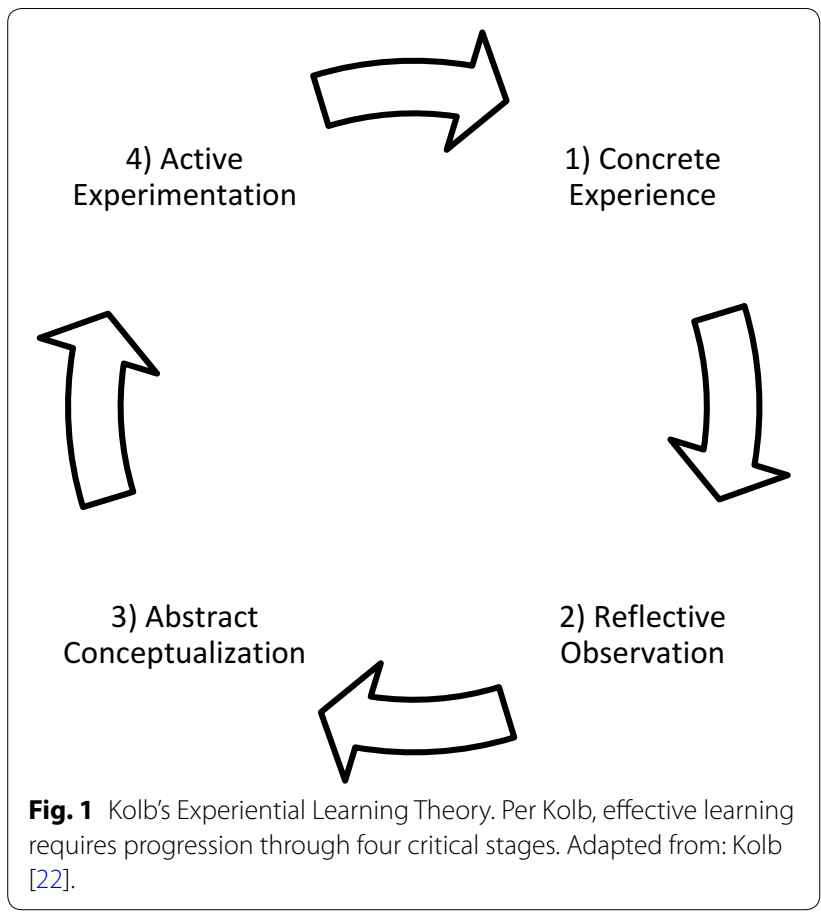

controlled fashion with ample time for reflection during each stage of clinical decision making.

Adult learners have educational needs unique from children that must be heeded (Table 1) [23]. Andragogy, the method and practice of teaching adult learners, suggests that Kolb's formulation is particularly applicable to healthcare professionals. Per Kolb, rote memorization of medical facts alienated from experiential learning is unlikely to effect lasting change in the learner. Benjamin Bloom described a taxonomy of educational objectives whereby remembering facts serves as the basest form of cognition. Understanding, applying, analyzing, evaluating, and creating are increasingly higher-order cognitive functions that loosely parallel the ACGME's milestone levels [24]. Simulation, through incorporation of major learning theories including behaviorism, constructivism, social constructivism, reflective practice, situated learning, and activity theory, provides a framework for helping learners to achieve Bloom's higher cognitive functions [25].

Table 1 The educational needs of adult learners. From: Bryan et al. [23]

Adults need to know why they are learning

Adults are motived by the need to solve problems

Adults' previous experience must be respected and built upon

The learning approach must match their background and diversity

Adults need to be actively involved in the learning process
Traditional lecture-based didactics fall short, in part, because they fail to engage learners. Simulation-based education, on the other hand, enhances engagement both through the inherent emotional aspects of the case and through the act of being observed. Highly activated states, even when including negative emotions, motivate learning and boost retention [26, 27]. Anxiety-provoking risk-taking is a critical aspect of engagement in simulation. Learners are encouraged to work at the edge of expertise where instructor assistance is needed to aid the learner's advancement [28]. Conversely, lack of psychological safety may undermine educational efforts, especially when professional or social identity is threatened. Creating a setting where learners feel safe enough to embrace being uncomfortable and free to practice new skills is what Jenny Rudolph describes as "establishing a safe container for learning in simulation [29]." Educators must create psychological safety for learners to improve the effectiveness of simulation-based education (see Table 2).

At least four decades of simulation education research have demonstrated its effectiveness in improving knowledge, skills, behaviors, and patient-related outcomes [30]. The Best Evidence Medical Education Executive Committee commissioned a review in 2001 to highlight the aspects of high-fidelity medical simulation that lead to the most effective learning. Results from their review reside in Table 3 [31]. While a complete description of each feature is beyond the scope of this review, a brief exploration of the most studied feature, feedback, is warranted.

Feedback is historically the most vaunted tool to promote effective learning [31]. Feedback sources in simulation include video recordings, peer observers or co-participants, the simulation device (e.g. the manikin/monitor or standardized patient), or facilitatorled debriefing. Necessity of debriefing depends on the learning objective and learner group likely to benefit [32]. Debriefing usually takes place after the simulation, but other methods such as on-demand learner-initiated debriefing or facilitator-initiated time-outs for debriefing can be utilized [33]. While a host of debriefing models exist [34-36], most contain four key steps: (1) noting performance gaps related to predetermined objectives,

Table 2 How to create psychological safety in simulation. From: Rudolph et al. [29]

Clarify objectives, roles, confidentiality, and expectations

Establish a "fiction contract" with participants

Attend to logistical details

Convey a commitment to respecting learners and understanding their perspective 
Table 3 Features of high-fidelity simulators that lead to effective learning. From: Issenberg et al. [31]

\begin{tabular}{|c|c|}
\hline Feature & Comment \\
\hline Feedback & Immediate assessment of performance and discussion of educational material \\
\hline Repetitive practice & Skill repetition that allows for the student to correct errors and improve overall performance \\
\hline Curriculum integration & Simulation-based medical education that is part of a standard curriculum, not an extracurricular activity \\
\hline Range of difficulty levels & Flexibility for the difficulty level to adjust based on the student's level of education \\
\hline Multiple learning strategies & $\begin{array}{l}\text { Learning in multiple environments including large groups, small groups, and small group or independent learning } \\
\text { without an instructor }\end{array}$ \\
\hline Capture clinical variation & Engaging the student in a wide variety of scenarios to which they may otherwise not be exposed \\
\hline Controlled environment & $\begin{array}{l}\text { An environment in which there are no adverse outcomes to patients, which allows for the focus to be on the student } \\
\text { and not on the patient }\end{array}$ \\
\hline Individualized learning & $\begin{array}{l}\text { Active participation in a series of complex tasks that can be broken down into component parts, which allows for the } \\
\text { mastery of each part at variable rates unique to each student }\end{array}$ \\
\hline Defined outcomes/benchmarks & Goals with tangible and objective measures \\
\hline Simulator validity & Degree of realism of the simulation \\
\hline
\end{tabular}

(2) providing feedback describing the gap, (3) investigating the basis for the gap by exploring the frames of the learner, and (4) helping to close the performance gap through discussion or instruction [37]. A meta-analysis of 46 studies found that team- and individual-level debriefing improves educational effectiveness by approximately $25 \%$ [38].

The success of the debriefing may rest on the skill of the facilitator or instructor. The effect of instructor training has been relatively understudied. Learners indicate that debriefer skill is the strongest contributor to the overall quality of simulation [39]. Despite that finding, less than half of all facilitators have had any debriefing training and less than $20 \%$ have had their competence as debriefers assessed [40]. Validated assessment tools for debriefing have been developed but remain underutilized [41, 42]. Due to costs associated with training and employing expert debriefers, self-assessment has gained in popularity following simulation. Unfortunately, evidence suggests that medical professionals are quite limited in their ability to self-assess [43]. The Society for Simulation in Healthcare and the International Nursing Association for Clinical Simulation both recommend specific instructor training for simulation debriefing $[44,45]$.

\section{Current Applications}

The current applications of simulation training in neurocritical care can be divided by simulator modality. The primary simulator modalities in use are task trainers, manikin-based simulators, standardized patients, and computer-based simulators.

\section{Task Trainers}

Task trainers are limited models of body parts designed to aid in the acquisition of technical or procedural skills.
They can be constructed as three-dimensional models of relevant anatomy or they can employ high-definition computer-based virtual modeling to build a hyper-realistic learning environment. High cost has been a limitation, but do-it-yourself task trainers provide an inexpensive option that may be valid for the task at hand [46, 47], while three-dimensional printers are expanding the modeling possibilities and increasing accessibility [48]. Deliberate practice is a pivotal feature of procedural learning on task trainers. Deliberate practice requires a welldefined goal, immediate feedback on performance, ample opportunities for practice, and sustained concentration [49]. Task trainers have been successfully employed to train learners in a variety of critical care procedures including: point-of-care ultrasound [50], airway management/intubation [51], bronchoscopy [52], thoracentesis [53], and paracentesis [54]. One of the real triumphs of simulation-based medical education research has been the demonstration of a reduction in central line associated blood stream infections in simulation-trained residents [55]. A meta-analysis found that simulation-based medical education with deliberate practice is superior to traditional clinical education for the acquisition of procedural skills [56]. By reducing the number of complications, simulation-based procedural training has been shown to be cost-effective as well $[57,58]$.

Among neurological skills, an optic nerve sheath diameter trainer has been validated [59], while fundoscopic exam and lumbar puncture task trainers have both exhibited benefit $[60,61]$. A study comparing the lumbar puncture skills of simulation-trained internal medicine residents to traditionally trained neurology residents found that the simulation-trained residents showed superior performance despite significantly less clinical experience with the procedure. Furthermore, few traditionally 
trained neurology residents were competent to perform the procedure, highlighting the inadequacies of the current standard training methodologies [62].

\section{Manikin-Based Simulators}

Manikin-based simulators are life-sized, programmable manikins capable of producing neurological and systemic physiological signs and responses. The SimMan 3G (Laerdal Medical, Wappingers Falls, New York), HAL S3201 (Gaumard Scientific, Miami, Florida), and The Human Patient Simulator (CAE, Sarasota, Florida) are examples of such devices. With some variation from manikin to manikin, they are capable of multiple airway and circulatory features and complications such as bilateral or unilateral chest rise and fall, variable lung compliance and resistance, carbon dioxide exhalation, normal or abnormal breath sounds, cyanosis, variable pulse strength, variable urine output, bleeding (both arterial and venous), secretions, diaphoresis, bowel sounds, and automatic drug recognition systems that identify the drug and dose and provide appropriate physiological responses to drug administration. Telemetry, oxygen saturation, end-tidal carbon dioxide, hemodynamic parameters, intracerebral pressure, and temperature can all be obtained and monitored. One can perform procedures such as insertion of peripheral or central intravenous lines, bag-mask ventilation, intubation (with or without airway complications), chest tube insertion, defibrillation and cardioversion, and cardiopulmonary resuscitation (with feedback regarding depth, frequency, and fraction of compressions).

Unfortunately, neurological responses are decidedly limited. As such, manikin-based simulation in its current iteration is a poor forum for teaching subtleties of the physical exam. The manikins can "speak" through integrated microphones that allow an instructor to speak as if they were the patient. The level of arousal is indicated by eye opening (open, partially open, or closed). Pupillary size and responsiveness can be manipulated, but other cranial nerve reflexes or motor functions are not possible. Seizures are simulated by a high frequency shaking action that lacks realism. Pediatric HAL (Gaumard Scientific, Miami, Florida), a recently developed pediatric patient simulator, is capable of more including head, facial, jaw, and eye movements (nystagmus) at great cost. Indeed, high cost is a major limitation of high-fidelity manikin-based simulators.

High-fidelity manikin-based simulation is also limited by their high labor costs. In most cases, simulations require at least two or three staff members to operate the simulator, aid the learners (often in the guise of a nurse confederate), and perform the debriefing. Several solutions can mitigate the labor costs. First, simulation scenarios can be pre-programmed to minimize the work of the operator. Second, although the number of handson learners is limited by the practical aspects of delivering care to a single patient, it can be expanded through the use of multidisciplinary teams. While four physicians may seem redundant, a team comprised of a physician, advanced practice provider, nurse, and respiratory therapist allows each to train in their specific role while facilitating teamwork and communication skill development. A final solution is to incorporate video technology or viewing stations through a one-way mirror to allow a second group of learners to observe and engage in debriefing. Many learners find being "on the other side of the glass" to be a rewarding educational experience.

Manikin-based simulators have been utilized in critical care to train teamwork skills [63], crisis resource management [64], evaluation and management skills [65], and for summative assessment $[66,67]$. Scenarios have been developed for most aspects of critical care management including blunt and penetrating traumatic injuries, small bowel obstruction, ruptured ectopic pregnancy, hemorrhagic shock, hyperkalemia, low urine output, heart block, post-operative atrial fibrillation, cardiogenic shock, myocardial infarction, endotracheal tube cuff leak, mucus plug, right main stem intubation, pneumothorax, asthma or COPD exacerbations, hypoxemic respiratory failure, narcotics overdose, malignant hyperthermia, septic shock, anaphylaxis, unstable ventricular tachycardia, and cardiac arrest [65, 66, 68-71].

High-fidelity manikin-based simulation has been demonstrated to be an effective learning tool in critical care and can be integrated into a longitudinal residency curriculum [72]. Medical students and residents learn more and perform better after simulation than after traditional training or problem-based learning without simulation $[65,73]$. In fact, first-year medicine residents who completed a simulation-based critical care educational intervention have demonstrated improved competency at the bedside of actual patients as compared to third-year residents who did not receive the intervention [74]. Learning retention may be enhanced as well. In a study of medical students in a tutorial of cardiovascular physiology, a single simulator session following the tutorial boosted immediate performance and performance one year later compared to students who only took part in a case discussion [75].

Perhaps the best studied area of simulation-based medical education is resuscitation. Simulation-based resuscitation training is considered valuable by learners and improves performance both in simulator-based codes and during actual codes in patients [76-78]. Advanced Cardiac Life Support (ACLS) skills learned through simulation resist decay. In a study of residents who received 
four two-hour simulator-based education sessions, ACLS skills significantly improved and were maintained 14 months following the intervention [79]. A meta-analysis of 182 studies involving 16,636 participants found that simulation-based training of resuscitation improved knowledge, skills, and patient outcomes when compared to no intervention regardless of level of learner [80]. The meta-analysis also found that simulation-based training improved learner satisfaction and skills when compared to non-simulation-based intervention. Simulation-based interventions were particularly effective when employed as "booster" practice, when focused on team/group dynamics, and when integrated with feedback.

The published experience in neurocritical care is more limited. In 2010, Musacchio et al. published their experience in using high-fidelity manikin-based simulation to train neurology and neurosurgery residents in the evaluation and management of spinal shock, closed head injury, and cerebral vasospasm. They found improvement on a multiple-choice exam following the simulation exercises and the resident's post-simulation impressions of the experience were overwhelmingly positive [81]. Simulations of brain death determination have demonstrated improved clinical performance and trainee confidence [82-84]. Brain death determination simulations have also raised awareness regarding the incompetence of many physicians who perform the determination. As a corollary, a study investigating mastery of status epilepticus management for pediatric residents found that prior to the intervention, none of the residents achieved satisfactory performance as measured by an observational checklist of required action items, but all met mastery standards following the intervention [85].

Acute stroke simulations have recently been described as a component of neurology residency training programs [86]. An approach that combined high-fidelity manikins with real patient videos to demonstrate neurological signs beyond the limits of the manikin yielded impressive gains in learner self-confidence for stroke assessment [87]. A similar approach with video augmented manikin training has been used to train spoke hospitals in a tele-stroke system resulting in significant improvements in knowledge in physicians, paramedics, nurses, and radiological technicians [88]. In a separate regional stroke network, high-fidelity manikin-based simulation in conjunction with crew resource management training reduced door-to-needle time and increased the portion of patients receiving thrombolysis within $30 \mathrm{~min}$ of hospital arrival [89]. Unfortunately, the vast majority of simulation-based education research in neurocritical care falls short of optimal methodological standards for educational research due to lack of controls and objective measures of performance.

\section{Standardized Patients}

Standardized patients are actors who have been trained to portray patients in a specific medical simulation in a consistent manner. These actors often excel in representing a variety of medical complaints and receive training in how to deliver feedback from the patient perspective. Unfortunately, trained standardized patients can be prohibitively expensive. In lieu of trained actors, many centers use volunteers (medical students, physicians, nurses, etc.) familiar with the disease of interest. Standardized patients have not featured in critical care simulation, but standardized family members have been successfully utilized to teach communication skills and ethical principles [90-92]. A modest literature describes the use of standardized patients in neurocritical care. In a recent study, trained actors were used to portray scenarios of myasthenic crisis and status epilepticus resulting in gains in knowledge and confidence in management [83]. In an interprofessional simulation in an epilepsy monitoring unit using both manikins and live actors, knowledge in seizure management was improved but confidence and performance were not [93]. Standardized patients have been used to train pre-hospital providers as well. Paramedics gained knowledge, clinical skill, and communication skill following a simulation-based intervention with actors portraying patients suffering acute strokes [94]. In general, standardized patients are preferred in two situations. First, standardized patients should be used when they are able to mimic exam findings that manikins cannot. For instance, many actors can authentically reproduce the hallmarks of a myasthenic crisis including fatigable weakness, nasal flaring, and paradoxical abdominal breathing. Second, standardized patients should be used when empathy and communication skills are emphasized.

\section{Computer-Based Simulation}

Computer-based simulation in which a computer interface replaces a physical immersive environment is an emerging simulation modality. Advantages include potentially lower cost to the learner, ease of distribution, and overall increased accessibility. Disadvantages include high upfront costs required to program simulations, limitations in the ability to modify simulations once programmed, and a relatively less immersive learning environment. While utilization of computerized virtual patients remains marginal, they hold promise for improving learning outcomes [95]. Much of the efforts in computer-based simulation have been focused on ACLS. One early study found that learners who used computerbased code simulators perform better in mock codes than those who used textbooks only to review [96]. This result was replicated in a more recent study in which access 
to a computer-based simulator as an adjunct to coursework was associated with reduction in time to defibrillate ventricular fibrillation and to pace symptomatic bradycardia [97]. The American Heart Association now offers computer-based simulation as part of its ACLS online course [98]. Other commercial packages for ACLS and critical care are available from Mad Scientist (Lehi, Utah), Laerdal Medical (Wappingers Falls, New York), and Anesoft (Laguna Niguel, California). More focused computer-based programs are also available, such as ultrasound or mechanical ventilator simulators $[99,100]$. Evolving research is testing the hypothesis that highfidelity manikin-based simulation is superior to a computer-based simulation for improving clinical skills. In a study comparing these two modalities in Acute Respiratory Distress Syndrome management, high-fidelity simulation yielded better results though the manikin-trained group may have had a test-retest advantage as the final assessment was performed using a manikin [101].

Neurological computer-based simulators are available as well. The Neurological Exam Rehearsal Virtual Environment is a free software suite of interactive virtual patients with cranial nerve pathology [102]. NewroSim ${ }^{\mathrm{TM}}$ is a computer-based mathematical modeling of cerebral perfusion simulating transcranial Doppler cerebral blood flow velocities that can mimic various pathological conditions. It can be run alone or in conjunction with a manikin-based simulator to simulate stroke or traumatic brain injury [103].

Fully immersive computer-based virtual reality environments have also been developed for medical simulation. They may be particularly useful for procedural skill training as advancing haptic feedback technology provides the learner with realistic tactile sensations. Pioneers in interventional neuroradiology have utilized a highfidelity endovascular virtual reality simulator to train physicians in mechanical thrombectomy for stroke [104]. Neurosurgeons have integrated virtual reality into surgical training with increasing success [105], but the technology remains an untapped resource in critical care and neurocritical care training. Manikins enhanced by virtual reality technology are feasible and may enhance the perception of realism during critical care management [106]. Virtual reality provides the opportunity for learners to practice in environments that are not easily recreated in a simulation laboratory, such as in the setting of a natural disaster or biochemical terror attack [107].

\section{Hybrid Simulators}

Simulator modalities can also be mixed to take advantage of individual features. For instance, a lumbar puncture task trainer could be used in conjunction with an anxious or confused standardized patient through careful draping. In this scenario, a gown and sterile towels could be placed to give the impression the lumbar puncture task trainer is actually part of the actor. This set-up could facilitate co-development of procedural and interpersonal skills.

\section{Future Directions \\ Technological Developments}

Exciting technological developments may hasten the integration of simulation into neurocritical care. Current low or high-fidelity manikin-based simulation is unable to faithfully recreate the complexities of the neurological exam. Advances are slowly becoming available to address the shortcomings. Manikins with eye movements and pupillary reaction are now commercially available for the first time. Improved haptic feedback mechanisms offer the very real possibility of future manikins capable of reproducing realistic motor exams. Virtual reality and augmented reality offer alternative solutions. Augmented reality layers computer-generated enhancements atop a physical space. A current example of this system is the collaboration between CAE Healthcare and the Microsoft Corporation (Redmond, Washington). CAE Healthcare's Vimedix AR ultrasound simulator combines a manikin-based ultrasound simulator with the Microsoft Hololens visor to allow learners in real time to view and manipulate anatomical structures in 3D space and appreciate how an ultrasound beam displays those structures. This technology has the potential of expanding the use of simulation in neurocritical care where current technology limits the creation of realistic neurological scenarios.

\section{Expanded Uses}

The technique of simulation can be applied far beyond trainee education. Simulation can be used for continuing medical education of physicians and allied health professionals as well as improving interprofessional education. The American Board of Anesthesiology endorses simulator-based education to fulfill their maintenance of certification requirement [108]. Simulation can also be utilized for performance assessment and high-stakes examinations [109]. As mentioned, the USMLE Step 2 Clinical Skills exam utilizes encounters with standardized patients. So too do the Medical Council of Canada Qualifying Examination Part II and the United Kingdom's General Medical Council Professional and Linguistic Assessments Boards Part 2. The Israeli Board of Anesthesiology incorporates simulation fully into its credentialing and certification examination [110]. The use of simulation as a high-stakes assessment tool requires an especially rigorous validation process of its anticipated measures, and proof of sufficient reliability [111]. This process has been carried out in various medical, surgical 
and critical care settings $[66,67,112,113]$, but remains to be undertaken in neurocritical care.

Simulation can be used as rehearsal for the purpose of practicing acute or complicated care, fostering interdisciplinary and interprofessional relationships and teamwork, or orienting staff to a new procedure, device, or locale. Simulators can also be used for research of organizational practices. Perhaps the highest profile simulation research did not evaluate simulation as an educational tool, but rather used simulation to evaluate the utility of surgical checklists in crisis scenarios [114]. Simulation can and should be used to probe organizational and human factors that affect performance $[1,115]$. Finally, simulation can test the usability of clinical devices in order to troubleshoot potential pitfalls prior to implementation into high-risk settings [116]. As new neurocritical care units are engineered, simulation could play an important role in testing unit design and functionality prior to opening the unit for actual patient care [117].

Simulation may have important medical-legal applications as well. The Consolidated Risk Insurance Company offers insurance premium incentives to select providers who participate in simulation-based crisis resource management as they have found the training to be effective in reducing malpractice claims associated costs [118]. Simulation has also been proposed as form of evidence in malpractice claims cases in order to prove or refute maleficence by the provider in question [118]. The future role of simulation in the courtroom remains to be determined.

\section{Translational Outcomes}

Translational outcomes can be described in terms of improved performance in the educational arena, improvements in performance in patient care, improved patient outcomes, and collateral outcomes such as cost savings or skill retention [119]. Literature supporting simulation-based medical education for improvement in translational outcomes is accumulating [2]. Current neurocritical care simulation-based education literature outcomes are limited to performance measures on educational metrics such as multiple-choice question testing or self-assessed knowledge. High methodological standards, such as the use of controls, are lacking. We need to push beyond these assessment methods to analyze performance-based measures both in simulated settings and, more importantly, at the bedside of real patients. We need to push even further to demonstrate real impact on patient outcomes.

Neurocritical care, as a relatively new field, has rightly maintained focus on conducting biomedical research with the aim of developing efficacious therapies to patients. There has been a dearth of interest and evidence in how to optimally educate clinicians to deliver the best care to patients. Simulation-based medical education is well suited to this task, but requires more rigorous study. Our colleagues in other critical care specialties have provided us the road map. For instance, through a series of experiments spanning several years, Barsuk and colleagues have shown that simulation-based central venous catheter insertion training improves learner performance in a sustained fashion, decreases complications in patients, saves money, and trickles down to learners who have not had the opportunity to participate in the simulation [55, 57, 120-122]. Per the authors, such an endeavor requires: "(1) highly motivated health professions learners; (2) curricula grounded in education science with learning goals and objectives that promote deliberate practice, rigorous measurement, feedback, mastery learning, and follow-up assessments; (3) educational resources including simulators, trained faculty, space, and training time; (4) intent to evaluate meaningful downstream results measured in different ways; (5) a research team that shares a variety of attributes that contribute to its productivity and morale; (6) reliance on rigorous quantitative, qualitative, and mixed research methods that produce reliable data that permit valid inferences and decisions; (7) sufficient research resources; and (8) a healthcare system that accepts simulation-based medical education trainees, values and reinforces translational outcomes, and implements the program scientifically [119]."

\section{Conclusion}

Despite Howard Barrow's role as a founding father of simulation, the neurology and neurocritical care community has lagged behind our colleagues in implementation of this pedagogy. While a growing body of literature supports simulation-based medical education in general critical care, more work needs to be done to include the application of simulation to neurocritical care education due to the unique complexities of neurological patients and the perceived primacy of the neurological exam which is challenging to recreate by current simulation technology. Further research is needed to validate neurocritical care simulation and establish its role in educational curricula. As medical simulation leader William C. McGaghie stated, improvement in performance and patient outcomes is "more likely to be achieved through educational and health services research programs that are thematic, sustained and cumulative rather than in single, one-shot studies [2]."

Barriers to simulation implementation include educational inertia, cost, and lack of trained faculty. The "see one, do one, teach one" apprenticeship model of medical education is deeply ingrained in healthcare culture, but 
needs to evolve given modern safety concerns and the educational theory recognizing adult learning issues.

Costs, though substantial, may be defrayed by sharing resources across academic departments. Many medical schools and hospital centers have already invested in the technology due to demand from other specialties that have embraced it. Without the initial outlays to establish simulation centers, new educators or researchers interested in simulation can explore their interest more frugally. One business model is to fund intramural projects using courses open to outsiders at a fee such as Basic and Advanced Cardiac Life Support, Advanced Trauma Life Support, Pediatric Advanced Life Support, or potentially Emergency Neurological Life Support.

A lack of trained faculty and opportunities for training in running simulations and debriefing remains a real hurdle. Simulation technology is a tool for excellent educators, not a replacement. Simulation fellowships are available and growing in number. Academic institutions must prioritize implementation science and reward educators through promotion and protected time to ensure that expensive simulation technology fulfills its promise in achieving optimal educational results [118].

Decades passed between acceptance and requirement for ACLS courses and evidence reporting improved outcomes [123]. This is a call to arms for neurocritical care educators and researchers to do better in establishing simulation-based education as a viable tool of healthcare delivery. We should engage in thoughtful and meticulous study to validate simulation, explore its potential, develop it as a learning platform, and learn its limitations in neurocritical care. We can and we must for our patients' sake.

\begin{abstract}
Author details
${ }^{1}$ Department of Neurology, Program in Trauma, University of Maryland School of Medicine, Baltimore, MD, USA. ${ }^{2}$ Departments of Neurology and Neurosurgery, New York University School of Medicine, New York, NY, USA. ${ }^{3}$ Department of Neurology, Wake Forest School of Medicine, Winston-Salem, NC, USA. ${ }^{4}$ Division of Neurocritical Care and Emergency Neurology, University of Maryland Medical Center, 22 S. Greene St, G7K18, Baltimore, MD 21201, USA.
\end{abstract}

\section{Acknowledgement}

The authors would like to thank Demian Szyld, MD, EdM who helped inspire this review.

\begin{abstract}
Author Contribution
NAM was involved in all aspects of the manuscript including conception and design, acquisition of data, analysis, interpretation, and drafting. BMC was involved in the conception and design of the manuscript, as well as critical revision of the manuscript for important intellectual content. AS was involved in the conception and design of the manuscript, as well as critical revision of the manuscript for important intellectual content. All authors made a substantial contribution to the conception and design, drafting the article or revising it critically for important intellectual content, and approved the version to be published.
\end{abstract}

\section{Source of support}

No funding.

\section{Compliance with Ethical Standards}

Conflict of interest

Dr. Morris reports the Faculty Innovation in Education Award from the American Board of Psychiatry and Neurology.

Published online: 25 October 2018

\section{References}

1. Gaba DM. The future vision of simulation in health care. Qual Saf Health Care. 2004;13(Suppl 1):i2-10.

2. McGaghie WC, Issenberg SB, Barsuk JH, Wayne DB. A critical review of simulation-based mastery learning with translational outcomes. Med Educ. 2014;48:375-85.

3. Hocker S, Wijdicks EF, Feske SK, Drislane FW. Use of simulation in acute neurology training: Point and counterpoint. Ann Neurol. 2015;78:337-42.

4. Albin C, Malaiyandi D. The state of neurocritical care simulation training: have we fallen behind? Currents 2018:32-3.

5. Pitts SR, Niska RW, Xu J, National Burt CW, Survey Hospital Ambulatory Medical Care. emergency department summary. Natl Health Stat Report. 2006;2008:1-38.

6. Hansen CK, Fisher J, Joyce N, Edlow JA. Emergency department consultations for patients with neurological emergencies. Eur J Neurol. 2011;18:1317-22.

7. Micieli G, Cavallini A, Santalucia P, Gensini G. Simulation in neurology. Neurol Sci. 2015:36:1967-71.

8. Schon F, Hart P, Fernandez C. Is clinical neurology really so difficult? J Neurol Neurosurg Psychiatry. 2002;72:557-9.

9. Barrows HS, Bennett K. The diagnostic (problem solving) skill of the neurologist. Experimental studies and their implications for neurological training. Arch Neurol. 1972;26:273-7.

10. Jozefowicz RF. Neurophobia: the fear of neurology among medical students. Arch Neurol. 1994;51:328-9.

11. Barrows HS. Problem-based, self-directed learning. JAMA. 1983:250:3077-80.

12. Barrows HS. An overview of the uses of standardized patients for teaching and evaluating clinical skills. AAMC Acad Med. 1993;68:443-51 (discussion 51-3)

13. Arora VM, Georgitis E, Siddique J, et al. Association of workload of on-call medical interns with on-call sleep duration, shift duration, and participation in educational activities. JAMA. 2008;300:1146-53.

14. Neurology Clerkship Core Curriculum Guidelines. 2000. Accessed May 27, 2017 https://www.aan.com/uploadedFiles/4CME_and_Train ing/2Training/3Fellowship_Resources/5Core_Curricula/skilz.pdf.

15. American Academy of Neurology Critical Care and Emergency Neurology Section Resident Core Curriculum. 2001. Accessed May 26, 2017 https://www.aan.com/uploadedFiles/Website_Library_Assets/Docum ents/8Membership/3People/5Sections/1Drop_down_for_33_sections/ Critical_Care_and_Emergency_Neurology/resident.pdf.).

16. The Neurology Milestone Project.

17. Promes SB, Chudgar SM, Grochowski CO, et al. Gaps in procedural experience and competency in medical school graduates. Acad Emerg Med. 2009;16(Suppl 2):S58-62.

18. Smith CM, Perkins GD, Bullock I, Bion JF. Undergraduate training in the care of the acutely ill patient: a literature review. Intensive Care Med. 2007:33:901-7.

19. Lazarou J, Hopyan J, Panisko D, Tai P. Neurology for internal medicine residents: working towards a national Canadian curriculum consensus. Med Teach. 2011;33:e65-8.

20. Sheth KN, Drogan O, Manno E, Geocadin RG, Ziai W. Neurocritical care education during neurology residency: AAN survey of US program directors. Neurology. 2012;78:1793-6.

21. Lerner DP, Kim J, Izzy S. Neurocritical care education during residency: opinions (NEURON) Study. Neurocrit Care. 2017;26:115-8. 
22. Kolb DA. Experiential learning: experience as the source of learning and development. Englewood Cliffs, NJ: Prentice-Hall; 1984.

23. Bryan RL, Kreuter MW, Brownson RC. Integrating adult learning principles into training for public health practice. Health Promot Pract. 2009;10:557-63.

24. A taxonomy for learning, teaching and assessing: A revision of Bloom's Taxonomy of educational objectives: Complete edition. New York: Longman; 2001.

25. Bradley P, Postlethwaite K. Simulation in clinical learning. Med Educ. 2003;37(Suppl 1):1-5.

26. Cahill L, McGaugh JL. Mechanisms of emotional arousal and lasting declarative memory. Trends Neurosci. 1998;21:294-9.

27. Zhao B. Learning from errors: the role of context, emotion, and personality. J Organ Behav. 2011;32:435-63.

28. Vygotsky L. Mind in society: the development of higher psychological processes. Cambridge, MA: Harvard University Press; 1978.

29. Rudolph JW, Raemer DB, Simon R. Establishing a safe container for learning in simulation: the role of the presimulation briefing. Simul Healthc. 2014;9:339-49.

30. Cook DA, Hatala R, Brydges $R$, et al. Technology-enhanced simulation for health professions education: a systematic review and metaanalysis. JAMA. 2011;306:978-88.

31. Issenberg SB, McGaghie WC, Petrusa ER, Lee Gordon D, Scalese RJ. Features and uses of high-fidelity medical simulations that lead to effective learning: a BEME systematic review. Med Teach. 2005;27:10-28.

32. Fanning RM, Gaba DM. The role of debriefing in simulation-based learning. Simul Healthc. 2007;2:115-25.

33. McMullen M, Wilson R, Fleming M, et al. "Debriefing-on-Demand": a pilot assessment of using a "pause button" medical simulation. Simul Healthc. 2016:11:157-63.

34. Rudolph JW, Simon R, Rivard P, Dufresne RL, Raemer DB. Debriefing with good judgment: combining rigorous feedback with genuine inquiry. Anesthesiol Clin. 2007;25:361-76.

35. Kolbe M, Weiss M, Grote G, et al. TeamGAINS: a tool for structured debriefings for simulation-based team trainings. BMJ Qual Saf. 2013;22:541-53.

36. Eppich W, Cheng A. Promoting Excellence and Reflective Learning in Simulation (PEARLS): development and rationale for a blended approach to health care simulation debriefing. Simul Healthc. 2015;10:106-15.

37. Rudolph JW, Simon R, Raemer DB, Eppich WJ. Debriefing as formative assessment: closing performance gaps in medical education. Acad Emerg Med. 2008;15:1010-6.

38. Tannenbaum SI, Cerasoli CP. Do team and individual debriefs enhance performance? A meta-analysis. Hum Factors. 2013;55:231-45.

39. Wilhelm J. Crew member and instructor evaluations of line oriented flight training. In: 6th international symposium on aviation psychology. Columbus, Ohio 1991, pp 362-7.

40. Fey MK, Jenkins LS. Debriefing practices in nursing education programs: results from a national study. Nurs Educ Perspect. 2015;36:361-6.

41. Brett-Fleegler M, Rudolph J, Eppich W, et al. Debriefing assessment for simulation in healthcare: development and psychometric properties. Simul Healthc. 2012;7:288-94.

42. Arora S, Ahmed M, Paige J, et al. Objective structured assessment of debriefing: bringing science to the art of debriefing in surgery. Ann Surg. 2012;256:982-8.

43. Davis DA, Mazmanian PE, Fordis M, Van Harrison R, Thorpe KE, Perrier L. Accuracy of physician self-assessment compared with observed measures of competence: a systematic review. JAMA. 2006;296:1094-102.

44. Committee for Accreditation of Healthcare Simulation Programs Teaching/Education Standards and Measurement Criteria. Accessed May 30th, 2018, http://www.ssih.org/Portals/48/Accreditation/2016\%20Sta ndards\%20and\%20Docs/Teaching-Education\%20Standards\%20and \%20Criteria.pdf.

45. Sittner BJ, Aebersold ML, Paige JB, et al. INACSL standards of best practice for simulation: past, present, and future. Nurs Educ Perspect. 2015;36:294-8.
46. Murphy DL, Oberfoell SH, Trent SA, French AJ, Kim DJ, Richards DB. Validation of a low-cost optic nerve sheath ultrasound phantom: an educational tool. J Med Ultrasound. 2017;25:96-100.

47. Zeiler FA, Unger B, Kramer AH, Kirkpatrick AW, Gillman LM. A unique model for ultrasound assessment of optic nerve sheath diamter. Can J Neurol Sci. 2013;40:225-9.

48. Grice T, Cartwright M, Zavitz J, Glass C, Danelson K, Sarwal A. 383: development of a homemade phantom for simulation to teach ultrasound guidance for spinal procedures. Crit Care Med. 2018;46:174.

49. Ericsson KA, Nandagopal K, Roring RW. Toward a science of exceptional achievement: attaining superior performance through deliberate practice. Ann NY Acad Sci. 2009;1172:199-217.

50. Lewiss RE, Hoffmann B, Beaulieu Y, Phelan MB. Point-of-care ultrasound education: the increasing role of simulation and multimedia resources. J Ultrasound Med. 2014;33:27-32.

51. Kennedy CC, Cannon EK, Warner DO, Cook DA. Advanced airway management simulation training in medical education: a systematic review and meta-analysis. Crit Care Med. 2014;42:169-78.

52. Kennedy CC, Maldonado F, Cook DA. Simulation-based bronchoscopy training: systematic review and meta-analysis. Chest. 2013;144:183-92.

53. Barsuk JH, Cohen ER, Williams MV, et al. Simulation-based mastery learning for thoracentesis skills improves patient outcomes: a randomized trial. Acad Med. 2018;93:729-35.

54. Barsuk JH, Cohen ER, Vozenilek JA, O'Connor LM, McGaghie WC, Wayne DB. Simulation-based education with mastery learning improves paracentesis skills. J Grad Med Educ. 2012;4:23-7.

55. Barsuk JH, McGaghie WC, Cohen ER, O'Leary KJ, Wayne DB. Simulationbased mastery learning reduces complications during central venous catheter insertion in a medical intensive care unit. Crit Care Med. 2009;37:2697-701.

56. McGaghie WC, Issenberg SB, Cohen ER, Barsuk JH, Wayne DB. Does simulation-based medical education with deliberate practice yield better results than traditional clinical education? A meta-analytic comparative review of the evidence. Acad Med. 2011;86:706-11.

57. Cohen ER, Feinglass J, Barsuk JH, et al. Cost savings from reduced catheter-related bloodstream infection after simulation-based education for residents in a medical intensive care unit. Simul Healthc. 2010;5:98-102.

58. Barsuk JH, Cohen ER, Feinglass J, et al. Cost savings of performing paracentesis procedures at the bedside after simulation-based education. Simul Healthc. 2014;9:312-8.

59. Zeiler FA, Unger B, Zhu Q, et al. A unique model for ONSD part II: inter/ intra-operator variability. Can J Neurol Sci. 2014:41:430-5.

60. Gupta DK, Khandker N, Stacy K, Tatsuoka CM, Preston DC. Utility of combining a simulation-based method with a lecture-based method for fundoscopy training in neurology residency. JAMA Neurol. 2017;74:1223-7.

61. McMillan $\mathrm{HJ}$, Writer $\mathrm{H}$, Moreau KA, et al. Lumbar puncture simulation in pediatric residency training: improving procedural competence and decreasing anxiety. BMC Med Educ. 2016;16:198.

62. Barsuk JH, Cohen ER, Caprio T, McGaghie WC, Simuni T, Wayne DB. Simulation-based education with mastery learning improves residents' lumbar puncture skills. Neurology. 2012;79:132-7.

63. Frengley RW, Weller JM, Torrie J, et al. The effect of a simulation-based training intervention on the performance of established critical care unit teams. Crit Care Med. 2011:39:2605-11.

64. Lighthall GK, Barr J, Howard SK, et al. Use of a fully simulated intensive care unit environment for critical event management training for internal medicine residents. Crit Care Med. 2003;31:2437-43.

65. Steadman RH, Coates WC, Huang YM, et al. Simulation-based training is superior to problem-based learning for the acquisition of critical assessment and management skills. Crit Care Med. 2006;34:151-7.

66. Boulet JR, Murray D, Kras J, Woodhouse J, McAllister J, Ziv A. Reliability and validity of a simulation-based acute care skills assessment for medical students and residents. Anesthesiology. 2003;99:1270-80.

67. Murray DJ, Boulet JR, Kras JF, Woodhouse JA, Cox T, McAllister JD. Acute care skills in anesthesia practice: a simulation-based resident performance assessment. Anesthesiology. 2004;101:1084-95.

68. Lee SK, Pardo M, Gaba D, et al. Trauma assessment training with a patient simulator: a prospective, randomized study. J Trauma. 2003;55:651-7. 
69. Boulet JR, Murray D, Kras J, Woodhouse J. Setting performance standards for mannequin-based acute-care scenarios: an examineecentered approach. Simul Healthc. 2008;3:72-81.

70. Murray DJ, Freeman BD, Boulet JR, Woodhouse J, Fehr JJ, Klingensmith ME. Decision making in trauma settings: simulation to improve diagnostic skills. Simul Healthc. 2015;10:139-45.

71. Boyle WA, Murray DJ, Beyatte MB, et al. Simulation-based assessment of critical care "Front-Line" providers. Crit Care Med. 2018;46:e516-22.

72. Sam J, Pierse M, Al-Qahtani A, Cheng A. Implementation and evaluation of a simulation curriculum for paediatric residency programs including just-in-time in situ mock codes. Paediatr Child Health. 2012:17:e16-20.

73. Schroedl CJ, Corbridge TC, Cohen ER, et al. Use of simulationbased education to improve resident learning and patient care in the medical intensive care unit: a randomized trial. J Crit Care. 2012;27(219):e7-13.

74. Singer BD, Corbridge TC, Schroedl CJ, et al. First-year residents outperform third-year residents after simulation-based education in critical care medicine. Simul Healthc. 2013;8:67-71.

75. Gordon JA, Brown DF, Armstrong EG. Can a simulated critical care encounter accelerate basic science learning among preclinical medical students? A pilot study. Simul Health. 2006;1:13-7.

76. Wayne DB, Butter J, Siddall VJ, et al. Simulation-based training of internal medicine residents in advanced cardiac life support protocols: a randomized trial. Teach Learn Med. 2005;17:210-6.

77. Wayne DB, Butter J, Siddall VJ, et al. Mastery learning of advanced cardiac life support skills by internal medicine residents using simulation technology and deliberate practice. J Gen Intern Med. 2006;21:251-6.

78. Wayne DB, Didwania A, Feinglass J, Fudala MJ, Barsuk JH, McGaghie WC Simulation-based education improves quality of care during cardiac arrest team responses at an academic teaching hospital: a case-control study. Chest. 2008;133:56-61.

79. Wayne DB, Siddall VJ, Butter J, et al. A longitudinal study of internal medicine residents' retention of advanced cardiac life support skills. Acad Med. 2006;81:S9-12

80. Mundell WC, Kennedy CC, Szostek JH, Cook DA. Simulation technology for resuscitation training: a systematic review and meta-analysis. Resuscitation. 2013:84:1174-83.

81. Musacchio MJ, Smith AP, McNeal CA, et al. Neuro-critical care skills training using a human patient simulator. Neurocrit Care. 2010;13:169-75.

82. Hocker S, Schumacher D, Mandrekar J, Wijdicks EF. Testing confounders in brain death determination: a new simulation model. Neurocrit Care. 2015;23:401-8.

83. Braksick SA, Kashani K, Hocker S. Neurology education for critical care fellows using high-fidelity simulation. Neurocrit Care. 2017;26:96-102.

84. MacDougall BJ, Robinson JD, Kappus L, Sudikoff SN, Greer DM. Simulation-based training in brain death determination. Neurocrit Care. 2014;21:383-91

85. Malakooti MR, McBride ME, Mobley B, Goldstein JL, Adler MD, McGaghie WC. Mastery of status epilepticus management via simulation-based learning for pediatrics residents. J Grad Med Educ. 2015;7:181-6.

86. Ermak DM, Bower DW, Wood J, Sinz EH, Kothari MJ. Incorporating simulation technology into a neurology clerkship. J Am Osteopath Assoc. 2013;113:628-35

87. Garside MJ, Rudd MP, Price Cl. Stroke and TIA assessment training: a new simulation-based approach to teaching acute stroke assessment. Simul Healthc. 2012;7:117-22.

88. Richard S, Mione G, Varoqui C, et al. Simulation training for emergency teams to manage acute ischemic stroke by telemedicine. Medicine (Baltimore). 2016:95:e3924

89. Tahtali D, Bohmann F, Kurka N, et al. Implementation of stroke teams and simulation training shortened process times in a regional stroke network - a network-wide prospective trial. PLoS ONE. 2017;12:e0188231.

90. Downar J, Knickle K, Granton JT, Hawryluck L. Using standardized family members to teach communication skills and ethical principles to critical care trainees. Crit Care Med. 2012;40:1814-9.

91. Downar J, McNaughton N, Abdelhalim T, et al. Standardized patient simulation versus didactic teaching alone for improving residents communication skills when discussing goals of care and resuscitation: a randomized controlled trial. Palliat Med. 2017:31:130-9.
92. Lorin S, Rho L, Wisnivesky JP, Nierman DM. Improving medical student intensive care unit communication skills: a novel educational initiative using standardized family members. Crit Care Med. 2006;34:2386-91.

93. Dworetzky BA, Peyre S, Bubrick EJ, et al. Interprofessional simulation to improve safety in the epilepsy monitoring unit. Epilepsy Behav. 2015;45:229-33.

94. Gordon DL, Issenberg SB, Gordon MS, LaCombe D, McGaghie WC, Petrusa ER. Stroke training of prehospital providers: an example of simulation-enhanced blended learning and evaluation. Med Teach. 2005:27:114-21.

95. Cook DA, Erwin PJ, Triola MM. Computerized virtual patients in health professions education: a systematic review and meta-analysis. Acad Med. 2010:85:1589-602.

96. Schwid HA, Rooke GA, Ross BK, Sivarajan M. Use of a computerized advanced cardiac life support simulator improves retention of advanced cardiac life support guidelines better than a textbook review. Crit Care Med. 1999;27:821-4.

97. Nacca N, Holliday J, Ko PY. Randomized trial of a novel ACLS teaching tool: does it improve student performance? West J Emerg Med. 2014:15:913-8.

98. HeartCode. Accessed June 12th, 2018, https://onlineaha.org/.

99. Lino JA, Gomes GC, Sousa ND, et al. A critical review of mechanical ventilation virtual simulators: is it time to use them? JMIR Med Educ. 2016;2:e8.

100. Blum T, Rieger A, Navab N, Friess H, Martignoni M. A review of computer-based simulators for ultrasound training. Simul Healthc. 2013;8:98-108.

101. Spadaro S, Karbing DS, Fogagnolo A, et al. Simulation training for residents focused on mechanical ventilation: a randomized trial using mannequin-based versus computer-based simulation. Simul Healthc. 2017:12:349-55.

102. Johnson TR, Lyons R, Kopper R, Johnsen KJ, Lok BC, Cendan JC. Virtual patient simulations and optimal social learning context: a replication of an aptitude-treatment interaction effect. Med Teach. 2014;36:486-94.

103. NewroSim ${ }^{\text {TM }}$. Accessed July 20th, 2018, at http://newrosim.accurateso lutions.eu/.

104. Liebig T, Holtmannspötter M, Crossley R, et al. Metric-based virtual reality simulation: a paradigm shift in training for mechanical thrombectomy in acute stroke. Stroke. 2018;49:e239-42.

105. Pelargos PE, Nagasawa DT, Lagman C, et al. Utilizing virtual and augmented reality for educational and clinical enhancements in neurosurgery. J Clin Neurosci. 2017:35:1-4.

106. Semeraro F, Frisoli A, Bergamasco M, Cerchiari EL. Virtual reality enhanced mannequin (VREM) that is well received by resuscitation experts. Resuscitation. 2009;80:489-92.

107. Andreatta PB, Maslowski E, Petty S, et al. Virtual reality triage training provides a viable solution for disaster-preparedness. Acad Emerg Med. 2010;17:870-6.

108. MOCA $2.0{ }^{\circledR}$ Part 4: Quality Improvement. Accessed June 13th, 2018, at http://www.theaba.org/MOCA/MOCA-2-0-Part-4.

109. Boulet JR. Summative assessment in medicine: the promise of simulation for high-stakes evaluation. Acad Emerg Med. 2008;15:1017-24.

110. Ziv A, Rubin O, Sidi A, Berkenstadt H. Credentialing and certifying with simulation. Anesthesiol Clin. 2007;25:261-9.

111. Boulet JR, Jeffries PR, Hatala RA, Korndorffer JR, Feinstein DM, Roche JP. Research regarding methods of assessing learning outcomes. Simul Healthc. 2011;6(Suppl):S48-51.

112. Kim J, Neilipovitz D, Cardinal P, Chiu M, Clinch J. A pilot study using high-fidelity simulation to formally evaluate performance in the resuscitation of critically ill patients: The University of Ottawa Critical Care Medicine, high-fidelity simulation, and crisis resource management I study. Crit Care Med. 2006:34:2167-74.

113. Erdogan A, Dong Y, Chen $X$, et al. Development and validation of clinical performance assessment in simulated medical emergencies: an observational study. BMC Emerg Med. 2016;16:4.

114. Arriaga AF, Bader AM, Wong JM, et al. Simulation-based trial of surgicalcrisis checklists. N Engl J Med. 2013;368:246-53.

115. Howard SK, Gaba DM, Smith BE, et al. Simulation study of rested versus sleep-deprived anesthesiologists. Anesthesiology. 2003;98:1345-55.

116. Agutter J, Drews F, Syroid N, et al. Evaluation of graphic cardiovascular display in a high-fidelity simulator. Anesth Analg. 2003;97:1403-13. 
117. Sarwal A, Carter J, Brashear A, Wilson J, Martin S, Johnson J. 1237: use of medical simulation to test new patient care environment in a critical care setting. Crit Care Med. 2016;44:385.

118. Okuda Y, Bryson EO, DeMaria S, et al. The utility of simulation in medical education: what is the evidence? Mt Sinai J Med. 2009;76:330-43.

119. McGaghie WC, Issenberg SB, Cohen ER, Barsuk JH, Wayne DB. Translational educational research: a necessity for effective health-care improvement. Chest. 2012;142:1097-103.

120. Barsuk JH, Cohen ER, Feinglass J, McGaghie WC, Wayne DB. Use of simulation-based education to reduce catheter-related bloodstream infections. Arch Intern Med. 2009;169:1420-3.
121. Barsuk JH, Cohen ER, McGaghie WC, Wayne DB. Long-term retention of central venous catheter insertion skills after simulation-based mastery learning. Acad Med. 2010;85:S9-12.

122. Barsuk JH, Cohen ER, Feinglass J, McGaghie WC, Wayne DB. Unexpected collateral effects of simulation-based medical education. Acad Med. 2011;86:1513-7.

123. Dane FC, Russell-Lindgren KS, Parish DC, Durham MD, Brown TD. Inhospital resuscitation: association between ACLS training and survival to discharge. Resuscitation. 2000;47:83-7. 